$$
\text { , }
$$ 


\section{Opereren in een mijnenveld van emoties}

Een therapeutisch proces belicht vanuit de interactionele invalshoek

Ayse Dogan en Nele Stinckens

- In dit artikel analyseren we het therapieverloop van een cliënte met borderlinepersoonlijkheidsproblematiek. We richten de focus in hoofdzaak op haar moeilijkheden in het relationeel functioneren, die zich ook herhaaldelijk manifesteren in het therapeutische contact. Volgehouden exploratie en doorwerken van deze moeilijkheden met een authentieke en betrouwbare therapeute heeft een ontmijnend effect: cliëntes gefrustreerde relationele behoeften worden erkend en ingevuld en ze slaagt erin een adaptievere interactiestijl te ontwikkelen. We gebruiken het Leuvens systematisch case study protocol (LSCP) om het therapieverloop systematisch door te lichten en, waar nodig, bij te sturen. Ofschoon dergelijke werkwijze tijdsintensief is en een extra mentale inspanning vraagt van beide partijen is de therapeutische winst groot: het protocol helpt zowel de cliënte als de therapeute om in relatieve rust, veiligheid en voorspelbaarheid het mijnenveld te betreden.

AYSE DOGAN, psychologe en cliëntgericht psychotherapeute in opleiding, is werkzaam in een algemeen ziekenhuis en een psychotherapeutisch centrum voor studenten van de KU Leuven.

NELE STINCKENS is cliëntgericht psychotherapeute, docente en onderzoekster aan de KU Leuven, Faculteit psychologische wetenschappen, afdeling klinische psychologie. Daarnaast werkt zij in een groepspraktijk voor psychotherapie.

Correspondentieadres: ayse.dogan@gmail.com

Dit artikel is een beknopte weergave van het specialisatieverslag dat de eerste auteur schreef in het kader van haar Postgraduaatopleiding cliëntgerichte psychotherapie aan de KU Leuven. De tweede auteur was promotor van dit verslag. 


\section{Opzet}

In dit artikel schetsen we het therapieverloop van een cliënte wier relationele problemen in sterke mate het contact met de therapeute kleuren. De heftige emotionele reacties die in het therapeutische contact worden geëvoceerd, zowel bij cliënte als therapeute, doen denken aan het 'doorkruisen van een mijnenveld': het is allerminst zeker of beiden het er veilig en ongeschonden zullen vanaf brengen. Concreet bestaat dit mijnenveld zowel uit verwachte als uit onverwachte alliantiemoeilijkheden in het therapeutische contact. Deze moeilijkheden zijn een weerspiegeling van de onderliggende relationele schema's, die de verhouding van cliënte met anderen bepalen. Het doorwerken van deze relationele schema's is de kern van het therapieproces. Om meer inzicht te bieden in de veranderingen die zich in de loop van de therapie voltrekken, maken we gebruik van het 'Leuvens systematisch case study protocol' (LSCP: Stinckens, Elliott \& Leijssen, 2009). Dit protocol brengt een gevarieerd palet van proces- en outcomeaspecten in kaart, die verband houden met gemeenschappelijke sleutelingrediënten in om het even welke therapie (zie tabel 1). Om de complexiteit en contextspecificiteit van het therapieproces te kunnen vatten worden de kwantitatieve metingen aangevuld met kwalitatieve bevragingen.

Tabel 1 Omschrijving van het onderzoekskader van het Leuvens systematisch case study protocol (LSCP)

\begin{tabular}{|c|c|c|c|}
\hline Domeinen & Instrumenten & Tijdstip afname & Aantal \\
\hline \multicolumn{4}{|l|}{ Therapie-outcome } \\
\hline Mate van symptoomreductie & $\begin{array}{l}\text { BSI-NL (Brief symptom inventory, } \\
\text { Nederlandstalig) }\end{array}$ & Voor elke tweede sessie & 21 afnamen \\
\hline $\begin{array}{l}\text { Retrospectieve beoordeling van } \\
\text { veranderingen }\end{array}$ & CVI (Cliënt veranderingsinterview) & $\begin{array}{l}\text { Na sessie } 10,20,30, \ldots \text { en } \\
\text { bij afsluiting therapie }\end{array}$ & $2^{*}$ afnamen \\
\hline \multicolumn{4}{|l|}{ Therapieproces } \\
\hline Kwaliteit van de werkalliantie & $\begin{array}{l}\text { WAV-12 (Werkalliantievragenlijst } \\
\text { verkort, Nederlandstalig) }\end{array}$ & Na sessie $3,5,10,15, \ldots$ & 11 afnamen \\
\hline $\begin{array}{l}\text { Gepercipieerde helpende en } \\
\text { storende gebeurtenissen }\end{array}$ & SBL (Sessiebeoordelingslijst) & Na elke sessie & 40 afnamen \\
\hline
\end{tabular}

* In totaal werden 3 CVI's afgenomen. De gegevens van het $3{ }^{e}$ interview konden niet verwerkt worden door de slechte opnamekwaliteit van de geluidsband. In samenspraak met cliënte werd besloten geen $4{ }^{e}$ interview af te nemen aangezien verschillende vragen uit het interview reeds aan bod waren gekomen in kader van een evaluatie van de therapie tijdens de laatste sessies.

De BSI-NL is de Nederlandstalige versie van de Brief symptom inventory (De Beurs \& Zitman, 2005), de verkorte vorm van de SCL-9o-R (Arrindell \& Ettema, 1986). Het is een zelfrapportage-instrument dat een eerste indicatie geeft van de ernst en de aard van de klachten waaraan cliënten lijden.

De CVI (Cliënt veranderingsinterview) is een kwalitatief diepte-interview dat werd ontwikkeld door Elliott, Slatick en Urman (2001) en vertaald door Franssen en Stinckens (2005). In het eerste deel wordt gevraagd naar cliënts visie op de veranderingen die zich in de loop van de therapie hebben voltrok- 
ken. Ook de veranderingen in negatieve zin komen aan bod. In het tweede deel worden de geïnventariseerde veranderingen nader bevraagd. Meer bepaald wordt gepeild naar cliënts kwalificatie van de veranderingen (in welke mate verwacht, hoe waarschijnlijk en hoe belangrijk), de aspecten waaraan de veranderingen worden toegeschreven (aspecten binnen én buiten therapie), de hulpbronnen waaruit cliënte heeft kunnen putten (persoonlijke sterktes, ondersteunende omgevingsfactoren) en de beperkingen die mogelijk geïnterfereerd hebben (persoonlijke zwaktes, belastende omgevingsfactoren).

De WAV-12 (Werkalliantievragenlijst, verkort) is de Nederlandstalige versie (Stinckens, Claes \& Ulburghs, 2009) van de Working alliance inventory (WAI: Horvath \& Greenberg, 1989). Het is een zelfrapportage-instrument dat diverse aspecten van de therapeutische relatie in kaart brengt. Het instrument is gebaseerd op het werkalliantiemodel van Bordin (1979), waarin drie dimensies centraal staan: de therapeutische band, de overeenstemming over therapiedoelstellingen en de overeenstemming over therapietaken.

De SBL (Sessiebeoordelingslijst) is de Nederlandstalige aanpassing (Vanaerschot, 1997) van de Helpful aspects of therapy (HAT: Llewelyn, 1988). De lijst bevat een reeks open vragen die peilen naar helpende of belangrijke gebeurtenissen in de therapiesessie. Ook wordt er gepeild naar storende processen.

De metingen gebeuren op regelmatige tijdstippen in de loop van het therapieproces om zicht te krijgen op de kleine, maar vaak cruciale verschuivingen die zich gaandeweg voordoen. De vragenlijsten worden in papieren versie voor of na de sessie door de cliënt zelf ingevuld en aansluitend aan de therapeut overhandigd. Het veranderingsinterview wordt afgenomen door een collega-therapeut en in de vorm van een verbatim transcript aan de therapeut bezorgd.

\section{Voorstelling cliënte}

\section{Aanmeldingsklachten}

Cliënte is een jonge vrouw van 21 jaar die zich aanmeldt in een ambulant therapeutisch centrum, op aanraden van haar sociale omgeving. Zij rapporteert vooral depressieve gevoelens, die periodiek terugkeren sinds haar puberteitsjaren. Ze beschouwt deze 'donkere kant' als eigen aan haar persoon; $z e$ is iemand die zich aangetrokken voelt tot de zwaarte van het leven. Hierbij is er tevens een sterke fascinatie voor de dood. Naast deze depressieve gevoelens geeft cliënte blijk van een negatief zelfwaardegevoel. In contact met anderen kan zij zich klein of zwak voelen. Zij lijkt anderen tevens te categoriseren als hoger of lager (sterker/zwakker) in vergelijking met zichzelf. Ook is er ambivalentie tegenover lichamelijk contact en afkeer/walging van seksualiteit. De cliënte tracht lichamelijk contact in zijn algemeenheid te vermijden, maar ervaart tegelijk ook een gemis aan intimiteit en fysieke affectie. Tevens stelt ze zich vragen bij haar seksuele identiteit. In haar puberteit was ze verliefd op een vriendin. Deze ervaring in combinatie met een wal- 
ging voor de mannelijke seksualiteit doen haar vragen stellen rond haar seksuele geaardheid. Een partnerrelatie heeft cliënte nog niet gehad; seksuele ervaringen evenmin.

Over haar gezin van herkomst vertelt cliënte dat ze een afstandelijk contact heeft met haar ouders, broer en zussen: zij probeert zowel lichamelijk als persoonlijk contact met hen te vermijden. Thuis zou er weinig aandacht geweest zijn voor emotionele belevingen. Kwetsbaarheid tonen wordt als zwakte ervaren en moeilijke/negatieve belevingen worden genegeerd.

Vanuit haar vrijetijdsbesteding, interesses en opleiding heeft cliënte wel enkele sociale contacten opgebouwd die zij als vruchtbaar ervaart. $\mathrm{Zij}$ beschouwt deze personen als verwanten die, net als zij, op een diepgaande manier in het leven staan en de zwaarte ervan opzoeken.

\section{Een interactionele blik op cliëntes problemen}

De problematiek van cliënte kan vanuit de interactionele visie binnen de cliëntgerichte therapie op diverse manieren gekaderd worden. Binnen de interpersoonlijke communicatietheorie interpreteren we de relationele moeilijkheden van de cliënte als verstoord interpersoonlijk gedrag (Kiesler, 1996; Van Kessel \& Lietaer, 1998). Dit houdt in dat haar relationeel functioneren gekenmerkt wordt door een hardnekkig, eenzijdig en extreem patroon. Ze neemt over het algemeen een actief-afstandelijke positie in in contact met belangrijke anderen. Hiermee drukt zij uit geen nabijheid te wensen, terwijl er in haar authentieke beleving een verlangen is naar verbondenheid. Deze afstandelijke positie fungeert als aanpassing aan relationele kwetsuren uit de voorgeschiedenis (Hafkenscheid, 2004). Correctieve emotionele ervaringen in de therapeutische relatie kunnen een opening bieden om deze rigide en beperkende relationele schema's bij te werken en een authentieker contact te doen ontstaan.

Haar problematiek kunnen we ook begrijpen vanuit het spanningsveld tussen twee fundamentele ontwikkelingstaken: enerzijds de behoefte aan autonomie en een eigen identiteit ontwikkelen, anderzijds de behoefte aan afhankelijkheid en erbij horen (Bouwkamp, 1999; Wollants, Missiaen \& Leys, 2004). In het relationele functioneren dient men onafgebroken te zoeken naar een evenwicht tussen deze twee fundamentele verlangens. De verhouding tot de sociale wereld kan op twee verschillende manieren verstoord zijn, met een 'doorschieten' in een van beide polen. Dit manifesteert zich concreet in de vermijding van elk interpersoonlijk contact, of omgelkeerd, in een volledig met de ander versmelten (Wollants \& Lietaer, 2000). Cliënte lijkt vooral te opteren voor de vermijdende opstelling.

Safran en Muran (2000) beschouwen alliantieproblemen in therapie als pogingen om met de spanning tussen beide polen om te gaan. Hiernaast kunnen alliantieproblemen ook te maken hebben met verschillen en onduidelijkheden in werkwijze en doelstellingen van therapie. In elk van de gevallen kan men de interactionele moeilijkheden van de cliënt bewerken door de alliantieproblemen te exploreren en te herstellen. Het doel van het therapeutische proces is cliënten alternatieve, constructievere relatiepatronen aan 
te bieden opdat zij flexibeler en vrijer kunnen omgaan met de wisselende relationele scenario's in de buitenwereld.

Sachse (1997) benadert interactiemoeilijkheden als incongruente communicatiepatronen; hij introduceert de term 'Spielstruktur' om deze incongruente communicatiepatronen te omschrijven. Met een Spiel tracht cliënte op indirecte manier haar interactionele behoeften te vervullen, maar de communicatiepatronen die deel uitmaken van dit Spiel kosten meer dan ze opleveren. Ze hebben namelijk een rigide en disfunctioneel karakter doordat ze gekleurd worden door interactionele vooronderstellingen (schema's) die hun oorsprong vinden in negatieve relationele ervaringen in de voorgeschiedenis. Het is de taak van de therapeut om de cliënt te helpen inzicht te verwerven in deze disfunctionele communicatiepatronen. Hiervoor is het nodig dat de therapeut 'asociaal' reageert op deze patronen, maar tegelijk complementair ingaat op de onderliggende interactionele behoeften van cliënt. Op deze wijze kan ze leren om op een authentieke en directe wijze haar behoeften na te streven in relatie tot anderen.

\section{Hulpvraag}

Cliënte heeft een ambivalente houding tegenover therapie. Therapie volgen bevestigt bij cliënte het gevoel 'psychisch gestoord te zijn' en het raakt ook aan haar kernschema: zich 'Rlein' of 'zwak' te voelen. Anderzijds gelooft zij niet dat zij voldoende reden heeft om in therapie te komen. Zij heeft in het verleden namelijk geleerd haar eigen moeilijkheden te relativeren. Eerder was cliënte zes maanden in therapie. Ze haakte ontevreden af, omdat de psychologe haar onvoldoende houvast bood en haar te weinig met de neus op de feiten drukte ('ze liet mij maar praten'). Vooral haar vrienden en haar zus hebben haar over de streep getrokken om opnieuw met therapie te beginnen.

Als hulpvraag formuleert cliënte dat zij wil dat de puzzelstukjes van haar leven in elkaar worden gepast. Ze wil vooral de oorzaak van haar problemen kennen, zonder dat ze verlangt naar gedragsverandering. Volgens Verheul, Van den Brink en Van der Velden (2000) vertonen cliënten met interactieproblemen aan het begin van de therapie doorgaans weinig motivatie tot gedragsverandering. Zij zijn eerder op zoek naar manieren om hun leefsituatie te stabiliseren. Daarnaast ervaren ze hun klachten als egosyntoon en zijn ze geneigd hun problemen extern te attribueren (Verheul en anderen, 2000). Sachse (1997) dringt er daarom op aan cliënten zelf de keuze te laten om al dan niet te veranderen

\section{Verloop van de therapie}

Wij bespreken hieronder de interactionele mijlpalen die zich in de loop van de eerste 40 therapiesessies voordoen. De beschrijvingen worden, mits relevant, aangevuld met commentaren na sessies ('postsessiecommentaren') van cliënte en therapeute. 
Van bij de aanvang van de therapie doet cliënte een tegenstrijdig appèl op de therapeute. Zij wil geconfronteerd worden met haar kwetsbaarheden, maar dit roept tegelijk ongenoegen bij haar op. Ze heeft behoefte aan een meer ondersteunende, zorgende aanpak, maar dit wordt eveneens met ongenoegen onthaald. Cliënte uit dit ongenoegen door de therapie en de verschillende aspecten van de werkrelatie herhaaldelijk in vraag te stellen. Ook betwijfelt ze of ze wel vorderingen maakt. De persoon van de therapeute en de therapie devalueert $z$ ij als volgt:

Zij is niet mijn type van persoon..... er is geen spontane aantrekking..... wat kan de therapeute mij nu bieden?..... wat kan zij nu doen dat helpend is?.... ik vraag mij af of dit zinvol is.... we babbelen over banale dingen.... ik zie geen vooruitgang..... de therapie biedt mij niks.......

Safran en Muran (2000) spreken hier van een 'confrontatiemarker': de cliënte uit rechtstreeks haar kwaadheid of ontevredenheid. Ook merken we signalen van 'vermijding' op: cliënte werkt niet mee aan bepaalde therapietaken (bijvoorbeeld focusing) en sluit zich af voor de therapeute. Hierin komt de gebrekkige veranderingsmotivatie van cliënte tot uiting (Sachse, 1997). Anderzijds kan deze vermijding ook een uiting zijn van een onvermogen om stil te staan bij haar innerlijke leefwereld (Vanaerschot, 2008).

In eerste instantie reageert de therapeute complementair op het Spielniveau van cliënte; ze komt tegemoet aan cliëntes vraag om geconfronteerd te worden en ze poogt de klachten en disfunctionele relationele gedragspatronen inzichtelijk te maken. Dit doet ze via verschillende ingangspoorten: empathische gissingen, verdiepende exploratieve vragen naar (onderliggende) belevingen, evocerende interventies, lichaamsgerichte interventies en focusing-oefeningen. Hierdoor raakt ze echter verstrikt in de disfunctionele dynamiek van cliënte en houdt ze deze mee in stand. Volgens Safran en Muran (200o) is dit in de beginfase van de therapie onvermijdelijk.

Doorheen het verdere verloop van de eerste fase blijken deze interventies echter steeds meer spanning op te roepen. De therapeute past daarom haar methodiek aan: ze maakt meer gebruik van empathisch volgende tussenkomsten, die een betere regulatie van de spanningsintensiteit in de sessies mogelijk maken (Vanaerschot, 2008). Ze helpt cliënte ook om haar grenzen te bewaken en een veilige ruimte te creëren. Dit doet ze door cliënte enerzijds aandachtig te maken voor haar innerlijke belevingen als dragers van betekenisvolle informatie en tegelijk te tonen hoe er respectvol kan worden omgegaan met haar grenzen door deze innerlijke signalen serieus te nemen (Vanaerschot, 2008): 
Ik merk dat ik mij in het contact met jou uitgedaagd voel om telkens over je grenzen heen te gaan en dat voelt niet goed voor mij. Je lijkt ditzelfde effect te hebben op de mensen in je omgeving en dit maakt mij bezorgd. Ik geloof namelijk niet dat dat de beste manier is om je vooruit te helpen, integendeel zelfs. Ik vind het belangrijk om rekening te houden met je grenzen en er respectvol mee om te gaan. Maar het is niet altijd gemakkelijk. Je lijkt tegenstrijdige verwachtingen te hebben naar mij toe waaraan ik niet helemaal kan voldoen. Ergens verwacht je van mij dat ik je confronteer met je kwetsbaarheden, maar dat maakt jou ook juist boos op mij. Tegelijk maakt het je ook boos als ik je niet confronteer. Soms geraak ik hier in verstrikt. (...) Ik zou het dan ook fijn vinden als je open bent over het effect van mijn tussenkomsten op jou zodat ik leer een beter evenwicht te vinden tussen voldoen aan jouw verwachtingen en zorgzaam omgaan met je grenzen.

De therapeute kiest er dus voor om mee te gaan in de weerstand van cliënte, in de overtuiging dat haar gedrag een authentieke behoefte aan zorg uitdrukt. Daarnaast beoogt de therapeute door deze metacommunicatieve feedback los te komen uit de disfunctionele dynamiek van cliënte en een werkbare afstand te vinden, wat volgens Safran en Muran (2000) een belangrijke stap is in de oplossing van alliantieproblemen.

Deze feedback wordt tot op zekere hoogte positief onthaald door cliënte, doordat het haar duidelijkheid verschaft over de vorm van samenwerking in therapie en haar eigen bijdrage hierin. De feedback doet ook haar innerlijk spanningsniveau dalen. Maar zij beleeft deze aanpassing in werkwijze ook als een 'bescherming' van haar kwetsbaarheid, wat haar gevoel van 'klein' en 'zwak' te zijn nog versterkt. Ook vreest zij hierdoor minder intensief aan het werk te zijn in therapie. Specifieke procestaken en oefeningen in verband met lichamelijkheid en de dimensie afstand-nabijheid passen namelijk beter in haar beeld van hoe er gewerkt moet worden aan haar problemen; deze bieden haar structuur. Het wegvallen van de 'oefeningen' maakt dat cliënte moeilijker zicht kan houden op hoe en waaraan er gewerkt wordt in therapie.

Deze negatieve belevingen krijgen de overhand en zorgen voor meningsverschillen tussen cliënte en de therapeute over de te volgen werkwijze en na te streven doelstellingen. Op een directe en transparante manier - via metacommunicatieve feedback - worden deze meningsverschillen besproken en geëxploreerd. De cliënte zegt hierover het volgende:

Ik voel me veiliger bij open communicatie, want dan wordt er duidelijkheid gecreëerd en dat geeft me meer houvast en ook opnieuw meer ruimte. 


\section{Sessie 11-20}

In het volgende deel van de therapie bevindt cliënte zich in een fragiel proces van hoge intensiteit (Warner, 1992). Met fragiele processen bedoelen we belevingswijzen waarin de cliënt moeilijk contact kan maken en houden met de eigen beleving en de intensiteit van haar emoties moeilijk kan reguleren. Dergelijke belevingswijzen doen zich vooral voor in relatie met anderen; men verliest dan gemakkelijk het contact met het eigen belevingsspoor. Bij een fragiel proces van lage intensiteit ervaart de cliënt zijn belevingen als vaag en kan hij er moeilijk contact mee maken. Een fragiel proces van hoge intensiteit betekent dat de cliënt zijn belevingen op een heel intense manier gewaar wordt en er volledig mee samenvalt; er is geen werkbare afstand meer om over de belevingen te reflecteren.

Niet volledig juiste benamingen of lichtjes afwijkende spiegelingen worden door cliënte als een grove inbreuk ervaren en bedreigen de stabiliteit van de therapeutische relatie; het voelt alsof ze moet strijden voor het bestaansrecht van haar belevingen. Dit is onder meer het geval na sessie 10, het moment waarop het CVI wordt afgenomen. Cliënte komt in contact met een andere therapeut die zij idealiseert, terwijl ze haar vertrouwde therapeute devalueert. Affectregulerende tussenkomsten die containment en verduidelijking bieden van deze negatieve belevingen zijn in dit stadium erg belangrijk:

Je bent echt pissed op mij. Kun je eens uitleggen waarom je zo kwaad op me bent, ik zou het echt graag begrijpen....

Vanaerschot (2008) benoemt deze interventiewijze als een empathische validering die de aandachtsregulatie van de innerlijke leefwereld van de cliënte ten goede komt. De therapeute vervult tevens een modelfunctie in het leren omgaan met moeilijke, agressieve gevoelens (Safran \& Muran, 200o). Het vraagt veel van de therapeute om deze negatieve belevingen blijvend op te vangen en te dragen. Het zet bij haar een heftige belevingsstroom in beweging, zoals blijkt uit haar postsessiecommentaar:

Ik voel mij boos worden, triest en angstig. Angstig dat ze gaat stoppen met de therapie. Boos omdat ze maar blijft kappen op mij. Maar ik kon moeilijk laten zien dat dit mij raakte. Ik probeerde mij vooral staande te houden en sterk. Dit leek als effect te hebben dat zij maar bleef doorgaan. Ik zei enkel dat het mij wel raakte. Op het einde van het gesprek was ik zo boos dat ik haar wou terugpakken. Het leek op dat moment wel een machtsstrijd te worden. Ik moet zien dat ik hieruit blijf. Maar daarnet was het mij echt te veel. 
De therapeute kiest er uiteindelijk voor om toch iets van haar belevingen te verwoorden om te vermijden in een machtsstrijd verwikkeld te geraken. In haar interventie geeft zij cliënte feedback over de uitwerking van haar gedrag, maar neemt ze tegelijk oolk de verantwoordelijkheid op voor haar eigen aandeel in de interactie. Dit gebeurt via zogenaamde impact disclosures, waarmee ze expliciet uiting geeft aan wat het gedrag van cliënte met haar doet (Kiesler, 1996; Safran \& Muran, 2000; Sachse, 1997). Het effect van deze zelfonthulling is dat cliënte niet alleen haar kwaadheid kan benoemen en laten zijn, maar ook voor het eerst haar verdriet kan toelaten.

De laatste twee sessies heb je misschien wel gezien dat ik geëmotioneerd was. Dat komt omdat het mij wel raakt wat er gebeurt tussen ons. Het maakte mij boos en verdrietig dat je zo negatief bent over de therapie. Ik doe zo hard mijn best, maar het is precies nooit goed genoeg en dat kwetst mij wel. Soms voel ik mij dan ook zo machteloos in het contact met jou.... Vorige week kon ik je dit niet vertellen omdat ik mij net als jij sterk wou houden en mijn kwetsbaarheid niet wou tonen. Net als jij wou ik niet dat je mij zwak of klein zou vinden, maar ik merk dat het blijft wringen en dat het eruit moet... $\mathrm{k}$ ben ook maar een mens en het doet mij pijn als je niet ziet hoezeer ik probeer mijn best te doen voor jou.... Toen ik er zo verder over nadacht, merkte ik dat wat er zich tussen ons afspeelt, hierbuiten ook lijkt te gebeuren in relatie tot je familie.

Tussen sessie 16 en 23 komt cliënte achtereenvolgens in een fragiel proces van lage en hoge intensiteit, waardoor ze moeilijk greep krijgt op haar belevingen en deze kan vasthouden noch reguleren (Warner, 1992). Concreet uit zich dit in dissociatieve klachten en automutilatiegedrag. De fragiele belevingswijze van cliënte is een signaal voor de therapeute om het interactionele werk te onderbreken en haar interventie- en interactiewijze aan te passen aan de fragiele belevingswijze van cliënte. Op inhoudsniveau probeert de therapeute te kaderen wat er precies gebeurt; op betrekkingsniveau tracht ze op veilige afstand, maar toch in het zicht van cliënte, te gaan staan door empathisch volgend aanwezig te blijven. Hierdoor helpt ze cliënte betekenis te geven aan haar zogenaamd 'gekke' gedrag en dit te herinterpreteren als een waardevol gegeven (Vanaerschot, 2008).

Sessie 21-30

Naarmate het proces vordert, blijkt de innerlijke ruimte van de therapeute zich te herstellen. Ze slaagt er beter in om een observerend-participerende positie in te nemen en het therapeutische proces te beschouwen als een gedeelde verantwoordelijkheid van zowel cliënte als haarzelf. Deze verschuiving blijft ook voor cliënte niet onopgemerkt: 
I heb het gevoel dat de therapeute het in het begin heel erg vond dat ze mij niet kon bieden wat ik eigenlijk nodig heb, namelijk geborgenheid of zoiets, en dat ik dat ook niet wou van haar. En dat ze zich daar nu op een of andere manier bij heeft neergelegd. Dat is mijn gevoel.

Hiermee gepaard blijkt ook cliënte geleidelijk beter in staat haar innerlijke ruimte af te grenzen en veilig te stellen. Verschillen van de therapeute doet haar niet langer 'klein' en 'onbeduidend' voelen en haar belevingen verliezen hierdoor niet langer hun bestaansrecht. Ze slaagt er geleidelijk in haar visie naast die van de therapeute te plaatsen en van hieruit een compromis te bereiken over de verschillende aspecten van de werkrelatie. Vanuit deze procesveranderingen ontstaat tevens de mogelijkheid om haar onderliggende behoeften aan autonomie en territoriale onschendbaarheid (Sachse, 1997) te erkennen en vervolgens meer nabijheid toe te laten:

Ik had het gevoel dat de band tussen ons op een of andere manier aan het herstellen is.... Een gevoel dat ik niet helemaal kan omschrijven, maar misschien ben ik opener? In elk geval voel ik me meer op mijn gemak en minder afblokkend, een belangrijke verandering en dus ook helpend.... Ik heb daarbij het gevoel dat er minder afstand is tussen ons beiden, wat de therapie enkel maar ten goede kan komen.

Sessie 31-40

De werkwijze en doelstellingen van cliënte en therapeute komen in deze fase meer op één lijn te liggen, aangezien cliënte beter begrijpt wat het probleem is en hoe hier aan gewerkt wordt. Hierdoor stijgt ook haar motivatie tot verandering. Daarnaast krijgt de therapeute steeds meer het 'mandaat' om dichterbij te komen en van betekenis te zijn. Een belangrijke mijlpaal voor cliënte is de ervaring om erkend te worden in haar diepste kwetsbaarheid:

T: Wat zou er gebeuren als je vader je echt zou vastpakken, wat zou er dan allemaal in jou kunnen gebeuren, qua belevingen, qua gevoelens, qua gedachten... op zo een moment?

C: Ja, dat zou gewoon..... Oh, alleen al de gedachte.... heel bedreigend, dat zou echt heel bëdreigend zijn, dat zou... te dicht, dat zou ik niet aankunnen, dat is zoals.... dat is mijn.... dat verwoordt het het beste, maar dat klinkt heel extreem, maar dat zou aanvoelen als een verkrachting denk $\mathrm{ik}$, of zoiets, ik wil verkrachtingen niet minimaliseren, maar dat is....

T: Het zou een soort verkrachting van je persoon zijn.... 
C: Ja, dat is mijn gevoel ja. Terwijl nu we er verder op doorbabbelen, vind ik dat gek dat ik dat zo extreem ervaar, maar het is wel mijn gevoel....

Cliënte heeft na deze sessie het gevoel 'genezen' te zijn, wat kan wijzen op een correctieve emotionele ervaring. Haar vertrouwen in de therapie stijgt verder. Ook kan zij haar positieve waardering expliciet in het contact uiten zonder dat dit bedreigend aanvoelt:

Ik wil dat jij weet hoe ik de therapie heb ervaren en dat je de positieve dingen ook hoort, want deze keer heb ik enkel goede dingen gezegd.

\section{Evaluatie van het therapieproces}

Aan de hand van het LSCP willen we het afgelegde therapietraject doorlichten. Concreet zullen we de kwantitatieve en kwalitatieve bevindingen bundelen om een antwoord te formuleren op de volgende vragen: Is cliënte wezenlijk veranderd? Hoe zijn deze veranderingen precies tot stand gekomen? Heeft de therapie wezenlijk bijgedragen tot deze veranderingen?

Is cliente wezenlijk veranderd doorheen het therapieproces?

Een eerste indicatie van een gunstig therapieresultaat kunnen we afleiden uit de mate van symptoomreductie, die af te lezen valt uit de opeenvolgende scores op de BSI-NL. Figuur 1 toont dat er zich in het algemeen geen significante daling voordoet in de ernst van de klachten.

BSI

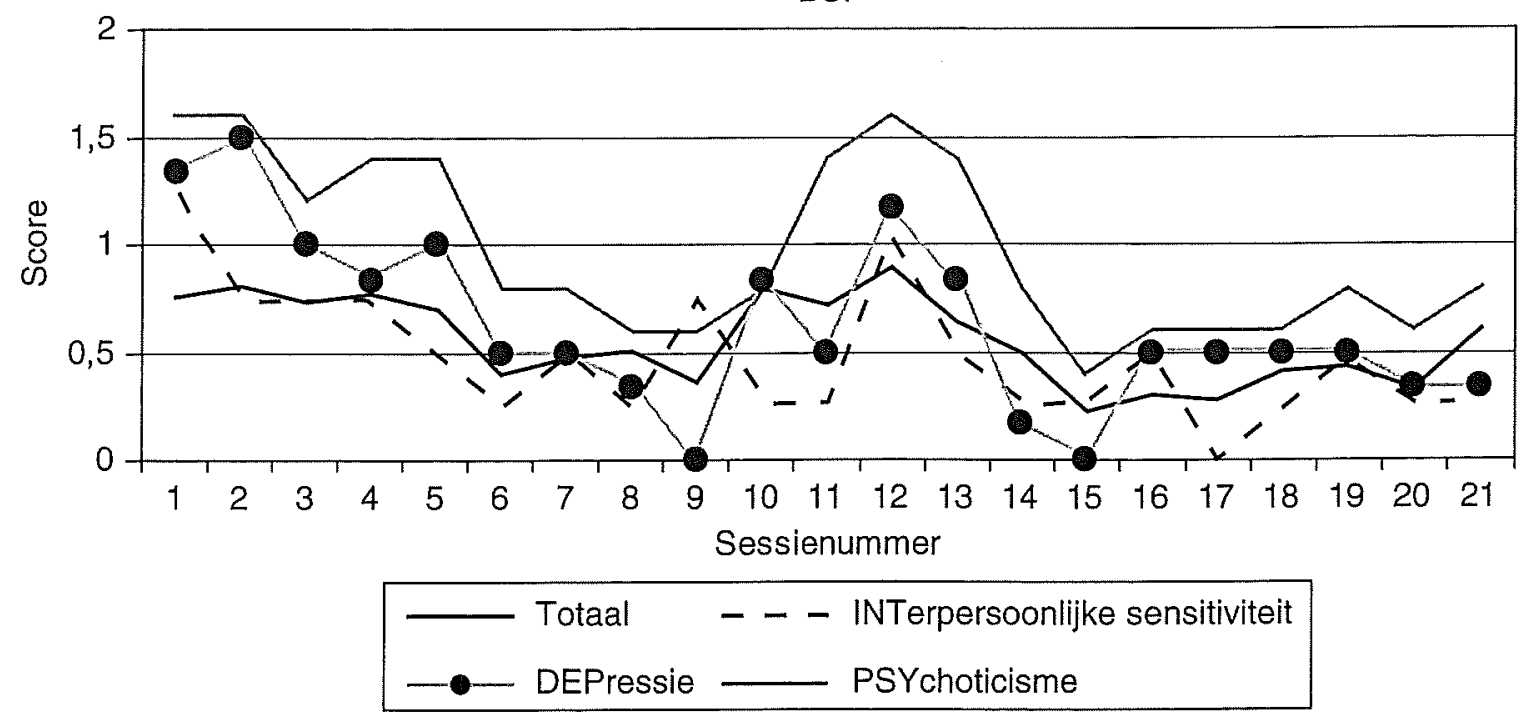

Figuur 1 Mate van symptoomreductie (BSI-NL) 
Hoewel cliënte zich op het einde van de therapie op een niet-klinisch niveau situeert (BSI-TOT $=0,60$ ) blijkt het verschil tussen initiële en eindscore niet significant te zijn $(\mathrm{RCI}=0,75)^{1}$. Wel telkenen er zich significante ${ }^{2}$ evoluties af in bepaalde subschalen, zoals interpersoonlijke sensitiviteit (onder andere: zich minder voelen dan anderen, makkelijk gekwetst voelen; depressie (onder andere: sombere stemming, suïcidale fantasieën, hopeloosheid) en psychoticisme (onder andere: geen verbondenheid voelen). Wat opvalt, is een uiterst grillig klachtenpatroon dat in de eerste plaats in verband kan gebracht worden met cliëntes persoonlijkheidsproblematiek. Zo blijkt haar klachtenpresentatie (in aard en ernst) te variëren naar gelang de belevingswijze waarin ze zich bevindt. Wanneer cliënte zich in een fragiel proces bevindt, stijgen de Totale BSI-scores alsook de subschaalscores voor verschillende dimensies, zoals angst, interpersoonlijke sensitiviteit, hostiliteit en psychoticisme. Daarnaast blijlkt de instabiliteit in klachtenpresentatie ook beïnvloed te worden door diverse contextfactoren. In de blok- en examenperiodes blijken haar klachten bijvoorbeeld te dalen naar een sublklinisch niveau. De examencontext verschuift de aandacht van cliënte van haar binnenwereld naar een externe context, wat rust met zich meebrengt. Tegelijk onttrekt zij zich gedurende deze periode aan haar sociale verplichtingen en dagdagelijkse activiteiten, zoals de therapie en de gezinscontext, waardoor de confrontatie met interactionele moeilijkheden en kwetsbare thema's vermindert. Ondanks de grilligheid in cliëntes klachtenverloop blijkt wel dat de tijdsduur waarin haar klachten zich op een niet-klinisch niveau situeren (BSI TOT < o,7o) in het tweede deel van de therapie toenemen. Dit kan wijzen op een positieve invloed van het emotieregulerend en interactioneel werken in therapie.

Om meer inzicht te lkrijgen in de cruciale veranderingsprocessen gedurende de therapie kan het CVI nuttige informatie aandragen. Cliënte geeft in het eerste interview aan helemaal geen veranderingen te zien die te maken kunnen hebben met de therapie. Ze lijkt het er moeilijk mee te hebben de gunstige effecten toe te schrijven aan de therapie en ze krijgt niets positiefs over haar lippen over de therapeute. Bij het nalezen van het uitgetypte interview zegt zij hierover spontaan het volgende:

Ik merk dat ik in heel dit interview steevast die vooruitgangen niet wil toeschrijven aan de therapie...... dit is zeer gek om te lezen...... $\mathrm{k}$ heb de indruk dat ik vooral niet wou toegeven dat het aan de therapie ligt dat ik me beter voel. Net of ik mezelf en ook Ayse niet kan gunnen dat therapie wel degelijk vorderingen met zich meebrengt..... ik geloofde er niet in...... Net of ik mijn probleemkens wel op mezelf zou oplossen en dat ik echt niet wil

1 RCI staat voor reliable change index (Jacobson \& Truax, 1991) en berekent of de vastgestelde verandering groter is dan wat op basis van de onbetrouwbaarheid van de meetprocedure te verwachten valt. De statistische toetsing gebeurt tweezijdig op een 0,05-signifiantieniveau.

2 Men spreekt over een betrouwbare verandering als $R C I>1,96$. 
dat anderen (mijn psycholoog) me daarbij zouden helpen en er zelfs ook in zouden slagen me beter te doen voelen.

Dergelijke reactie is te begrijpen vanuit de relationele problematiek van cliënte (Sachse, 1997). Er leeft een sterke angst voor afhankelijkheid van anderen. Haar autonomie is belangrijk voor haar, omdat zij zichzelf in het verleden leek te verliezen in anderen. Zich engageren in een positief werklklimaat met de therapeute roept eveneens angst op. Hoewel cliënte herhaaldelijk communiceert geen zorg of nabijheid van de therapeute te wensen, heeft ze toch ook behoefte aan een nauwer en intiemer contact (zo drukt cliënte de wens uit om met de therapeute iets te gaan drinken of na de therapie contact te houden). Cliënte geeft pas tegen het einde van de therapie expliciet uiting aan deze behoefte. Naarmate het proces vordert, slaagt ze er beter in het therapieproces op een genuanceerde manier te evalueren. In tabel 2 worden de veranderingen geinventariseerd die cliënte vermeldt in het tweede interview. Ze zijn gerangschilkt volgens de mate van belangrijkheid die cliënte eraan toekent - het merendeel van de veranderingen ervaart ze als 'erg belangrijk'. Wat de aard van de veranderingen betreft, blijken de meeste veranderingen zich te voltrelkken op interactieniveau: ze voelt zich minder klein in het contact met anderen, ervaart meer evenwaardigheid en durft ook meer te verschillen van anderen. Ze kan ook op een constructievere manier haar frustraties uiten en stilstaan bij moeilijke belevingen, zonder te ageren.

Tabel 2 Gerapporteerde veranderingen CVI-2

\begin{tabular}{|c|c|c|c|}
\hline VERANDERINGEN & $\begin{array}{l}\text { Mate van belangrijk- } \\
\text { heid }\end{array}$ & $\begin{array}{l}\text { Mate waarin ver- } \\
\text { wacht/verrast }\end{array}$ & $\begin{array}{l}\text { Waarschijnlijkheid in- } \\
\text { dien niet in therapie }\end{array}$ \\
\hline $\begin{array}{l}\text { Ik ben minder afhankelijk van } \\
\text { anderen, voel me steviger in } \\
\text { mijn schoenen staan }\end{array}$ & Erg belangrijk & Niet verrast & Eerder onwaarschijnlijk \\
\hline Ik ben minder onzeker & Erg belangrijk & Beetje verwacht & $\begin{array}{l}\text { Noch waarschijnlijk, noch } \\
\text { onwaarschijnlijk }\end{array}$ \\
\hline Ik weet beter wat ik wil & Erg belangrijk & Niet verrast & Eerder onwaarschijnlijk \\
\hline $\begin{array}{l}\text { Ik kan mezelf beter aanvaar- } \\
\text { den en ook mijn gevoelens }\end{array}$ & Erg belangrijk & Beetje verrast & $\begin{array}{l}\text { Noch waarschijnlijk, noch } \\
\text { onwaarschijnlijk }\end{array}$ \\
\hline $\begin{array}{l}\text { lk ben authentieker in het con- } \\
\text { tact met anderen, ik durf } \\
\text { spontaner zijn }\end{array}$ & Erg belangrijk & Verwacht & Eerder onwaarschijnlijk \\
\hline $\begin{array}{l}\text { Ik voel me in het algemeen } \\
\text { beter en stabieler }\end{array}$ & Erg belangrijk & Beetje verwacht & $\begin{array}{l}\text { Noch waarschijnlijk, noch } \\
\text { onwaarschijnlijk }\end{array}$ \\
\hline Ik durf makkelijker zorg vragen & Matig belangrijk & $\begin{array}{l}\text { Niet verwacht, niet } \\
\text { verrast }\end{array}$ & Beetje onwaarschijnlijk \\
\hline Ik heb meer afstand van thuis & $\begin{array}{l}\text { 'Het is gewoon zo, spijtig } \\
\text { en toch goed.' }\end{array}$ & Een beetje verrast & Zeer onwaarschijnlijk \\
\hline
\end{tabular}


Deze authentiekere communicatiewijze was voor haar voorheen niet haalbaar. Het geeft aan dat zij een weg heeft afgelegd in de therapie, wat haar de mogelijkheid biedt om zich te tonen in haar kwetsbaarheid zonder de angst om afgewezen te worden.

\section{Heeft de therapie bijgedragen tot deze veranderingen?}

Hoewel cliënte aanvankelijk aangeeft weinig uit het therapeutische aanbod gehaald te hebben, blijkt uit de kwalificaties van het CVI dat zij een vrij grote waarde toekent aan de therapie. De meeste veranderingen acht zij een beetje tot zeer onwaarschijnlijk zonder de hulp van de therapeute (zie tabel 2). Ook geeft cliënte in elke Sessiebeoordelingslijst aan dat zij iets werkelijk helpends of belangrijks ervaren heeft. Uit een analyse van haar antwoorden op de SBL blijkt dat cliënte het gevoel van erkenning, waardering en oprechte interesse als uitermate helpend en corrigerend heeft ervaren. Ook de structurerende en inzichtgevende tussenkomsten (het bespreken van de doelstellingen, werkwijze en proces van de therapie, het benoemen van gedragspatronen, het metacommuniceren over de therapeutische relatie) vermeldt zij als uitermate belangrijke gebeurtenissen. Als hinderlijkste aspecten ervaart zij het niet-spontane karakter van de relatie met de therapeute ('er is geen spontane klik', 'zij staat anders in het leven dan ik', 'ik kijk niet op naar haar') en de bij momenten onaangepaste empathische afstemming ('de therapeute komt te dicht' of 'ze begrijpt me niet') en het niet geheel correct spiegelen van de belevingen van cliënte.

Hoewel cliënte specifieke procestaken zoals focusing of andere lichaamsgerichte interventies als spanningsinducerend ervaart, waardeert ze het structurerende karakter hiervan. Zij krijgt hierbij steeds de vrijheid om al dan niet te participeren en wordt gestimuleerd om haar grenzen aan te geven. Ook de grenzen die de therapeutische relatie met zich meebrengt (beroepsgeheim, geen afhankelijkheidsrelatie, geen sociale controle enzovoort) bieden de nodige veiligheid voor haar om zich te tonen. Dat cliënte na ellke sessie een helpende gebeurtenis vermeldt, is in zekere zin strijdig met haar vaak geuite commentaar dat er onvoldoende gewerkt wordt in de therapie. Wellicht kan deze tegenstrijdigheid gekaderd worden vanuit de prestatiedruk die zij zichzelf en de therapeute oplegt en vanuit haar fragiele-proceskenmerken (gebrekkige zelfcontinuitteit, relationele onveiligheid, gepolariseerde perceptie).

Hoe zijn de veranderingen precies tot stand gekomen?

De therapie heeft bijgedragen tot deze veranderingen door de relationele schema's van cliënte uit te dagen en te corrigeren (Sachse, 1997). Vanaf het begin maakt de therapeute deel uit van het probleem waarmee cliënte zich aanmeldt: de disfunctionele schema's van cliënte worden in het contact met de therapeute geactiveerd en geageerd (Sachse, 1997). De eerste en voornaamste therapeutische taak is dan ook: een positieve werkrelatie met cliënte proberen te bewerkstelligen. Pas daarna kunnen de inhoudelijke thema's waar- 
mee zij worstelt, geëxploreerd worden. Een veilig en betrouwbaar milieu garanderen is hierbij essentieel, opdat cliënte überhaupt de spanningen kan verdragen die behoren tot het opbouwen van een werkrelatie (Swildens, 1997). Dergelijk milieu impliceert de grondhoudingen van echtheid, respect en gedoseerde empathie die kunnen bijdragen tot corrigerende relationele en emotionele ervaringen. Cliëntes gefrustreerde behoeften betreffen namelijk het relationeel niveau en kunnen ook het best opgeheven worden in het contact met de therapeute. Anderzijds heeft cliënte nood aan een procesexpert die een goed zicht heeft op de zaak en de touwtjes op dat niveau in handen neemt (Sachse, 1997). Metacommunicatie en transparantie over de interactie spelen hierbij een cruciale rol als hulpmiddel voor zowel cliënte als therapeute.

Met behulp van de WAV-12 kunnen we meer zicht krijgen op diverse aspecten van de therapeutische relatie. Uit figuur 2 kunnen we afleiden dat de initiële scores op de WAV-12 vrij laag zijn, zowel de totaalscore $(2,78)$ als de scores op de taak- en doeldimensies (Taak=2,6; Doel=2,8). Cliënte en therapeute verschillen aanvankelijk in hun visie op de doelstellingen van de therapie. Cliënte wenst vooral inzicht te krijgen in haar (dis)functioneren om haar leven draaglijker te kunnen maken, zonder een duidelijke vraag naar gedragsverandering: 'ik wil dat de puzzelstukjes in elkaar gepast worden', 'ik wil weten waarom ik ben zoals ik ben'. De therapeute van haar kant kadert de problematiek van cliënte als een interactieprobleem, wat maakt dat zij de nadruk legt op een positieve werkrelatie en het doorwerken van de relationele moeilijkheden. Deze doelstelling stemt niet overeen met de verwachtingen van cliënte. Daarnaast is er bij aanvang ook een verschil in visie op de efficiëntste werkwijze. Cliënte is ervan overtuigd het meest te kunnen groeien via een 'harde aanpak' met confronterende interventies en een rationele uitleg. Hoewel de therapeute hier in eerste instantie complementair op ingaat, verandert zij geleidelijk haar methodiek en stelt ze een 'asociale', niet-complementaire respons: ze confronteert cliënte niet langer, maar probeert haar empathisch te volgen en zorg te dragen voor haar grenzen. Dit interactieaanbod staat in schril contrast met de relationele geschiedenis van cliënte; het wekt bij haar dan ook het gevoel op van onvoldoende te werken aan haar probleem en slechts oppervlakkig bezig te zijn. 


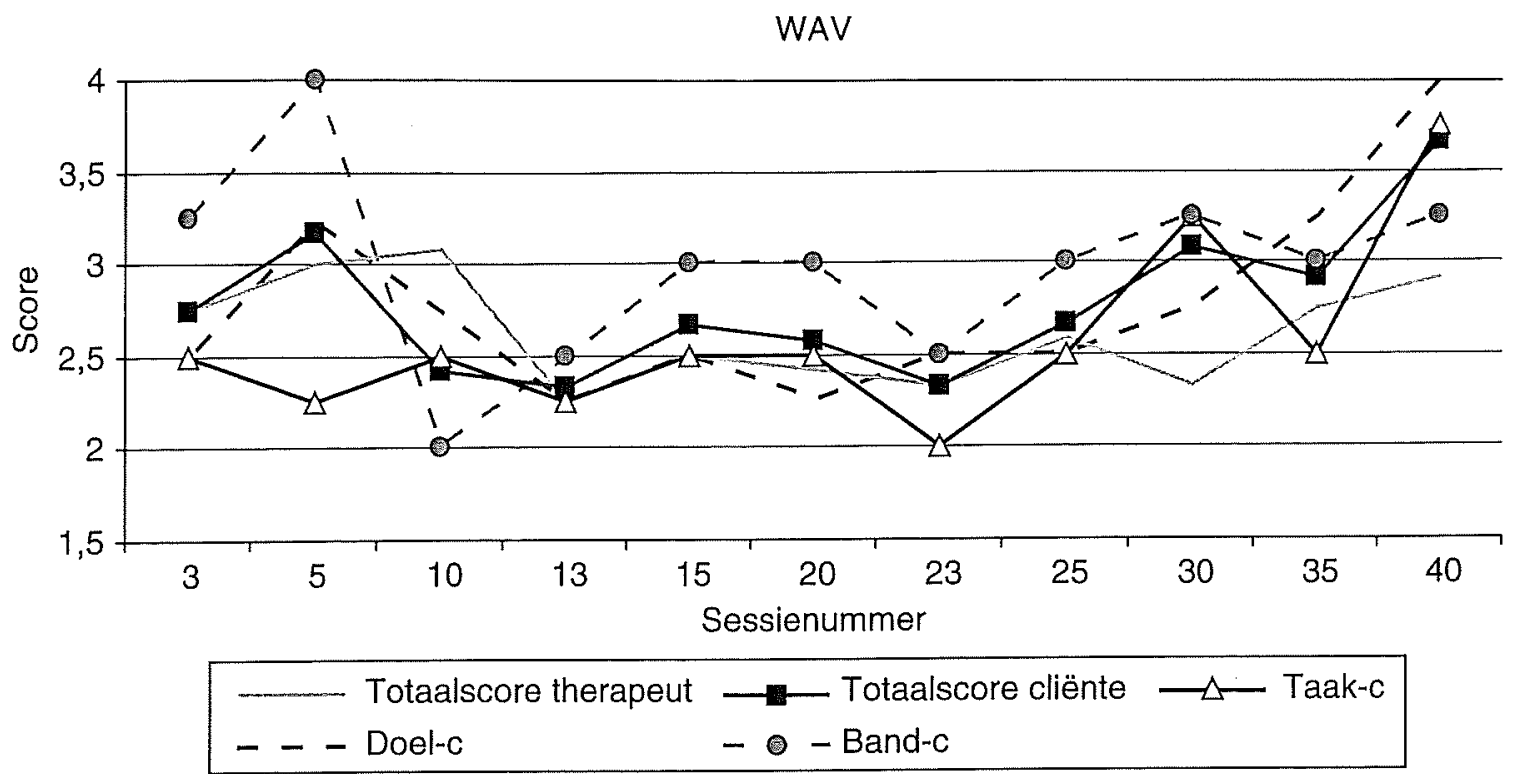

Figuur 2 Kwaliteit van de therapeutische relatie (WAV-12)

Vanaf sessie 23 zien we een geleidelijke stijging in de WAV-scores van cliënte en deze trend zet zich voort in de daaropvolgende sessies. Ook komen cliënte en therapeute doorheen het therapeutische proces meer op één lijn te staan met betrekking tot de werkwijze en doelstellingen van therapie $\left(\mathrm{r}_{\text {taak }} \mathrm{c}-\mathrm{t}\right.$ sessie

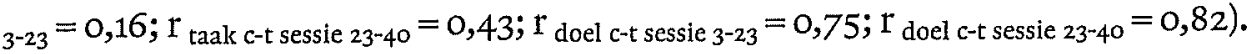
Wat de relationele band betreft, is er weinig overeenkomst tussen cliënte en de therapeute $\left(\mathrm{r}_{\text {band } c-t}\right.$ totaal $=-0,10$ ); dit geldt doorheen de gehele therapie.

Bij vergelijking van de Totale WAV-scores bij aanvang en einde van het onderzoek is er een significante verbetering merkbaar in de werkalliantie $(\mathrm{RCI}=\mathbf{2 , 2 4})$. Via het exploreren, inzichtelijk maken en corrigeren van de relationele kernschema's achter de alliantieproblemen krijgt cliënte een duidelijker beeld van haar problematiek. Hierdoor is zij tevens beter in staat om te reflecteren over meer aangepaste strategieën om haar moeilijkheden aan te pakken en stijgt haar motivatie tot gedragsverandering (Safran \& Muran, 2000).

\section{Besluit}

Met een combinatie van relationele en structurerende ingrediënten heeft de therapeute haar cliënte ongeschonden doorheen het mijnenveld van emoties geloodst. Het dynamiet onder deze emoties waren cliëntes relationele vooronderstellingen, die aanleiding gaven tot tal van alliantiemoeilijkheden. De volgehouden exploratie en doorwerking van deze moeilijkheden met een betrouwbare gids van vlees en bloed, had een ontmijnend effect: clientes gefrustreerde relationele behoeften werden erkend en ingevuld en cliënte slaagde erin haar disfunctionele relatiepatronen te doorbreken. Ze riskeerde het om haar vertrouwde actief-afstandelijke positie te verlaten, zowel in con- 
tacten met anderen als in relatie tot haar innerlijke belevingswereld. Dit zorgde voor meer stabiliteit, evenwaardigheid en authenticiteit in haar relationele functioneren.

Essentieel doorheen gans het parcours was dat de therapeute herhaaldelijk haar eigen belevingen en relationele behoeften onder de loep nam. Zonder een openheid en mildheid naar zichzelf toe was het een onmogelijke opdracht geweest om cliënte tegemoet te komen in haar relationele behoeften. Door systematisch het verloop van de therapie te bevragen kreeg zowel cliënte als de therapeute onmiddellijk feedback over het verloop van het therapieproces. Deze feedback bood beiden de gelegenheid korter op de bal te spelen en dreigende alliantiemoeilijkheden sneller aan te kaarten. Het hielp hen ook om met relatieve rust, veiligheid en voorspelbaarheid het mijnenveld te betreden, omdat het monitoring-instrument voorzag in explicietere wegwijzers en waarschuwingstekens.

Therapeuten die het systeem wensen te implementeren moeten zich wel realiseren dat het een behoorlijke investering vraagt. Ofschoon het protocol vooral bestaat uit korte vragenlijsten die in een korte tijdsspanne (maximaal 10 minuten) kunnen ingevuld en verwerkt worden, vraagt het van zowel cliënt als therapeut meer werk en organisatie. Naast deze praktische aspecten is er ook een bijkomende mentale belasting: het engagement van beide partijen voor het therapeutische gebeuren is minder vrijblijvend doordat men op regelmatige basis gevraagd wordt om rond diverse aspecten van het therapeutisch proces te reflecteren en te metacommuniceren.

De therapie en de therapeut worden daarenboven meer 'in de kijker' gezet. Dit vraagt enerzijds stevigheid van de therapeut en een niet-defensieve opstelling. Anderzijds 'dwingt' het de therapeut ook tot meer flexibiliteit, doordat ze expliciet met het perspectief van de cliënt dient rekening te houden. Deze uitdaging is des te groter wanneer men werkt met cliënten met ernstige persoonlijkheidsproblemen wier spoor vaak weinig voorspelbaar en rechtlijnig is.

\section{Literatuur}

Arrindell, W.A. \& Ettema, J.H.M. (1986). SCL-9o: Handleiding bij een multidimensionele psychopathologie-indicator. (SCL-9o: Manual for a multidimensional indicator of psychopathology). Lisse: Swets \& Zeitlinger.

Bordin, E. (1979). The generalizability of the psycho-analytic concept of the working alliance. Psychotherapy: Theory, Research and Practice, 16, 252-260.

Bouwkamp, R. (1999). Helen door delen. Experiëntiële interpersoonlijke therapie. Theorie, methodiek, onderzoek. Maarssen: Elsevier/De Tijdstroom.

Beurs, E. de \& Zitman, F. G. (2005). De Brief Symptom Inventory (BSI). De betrouwbaarheid en validiteit van een handzaam alternatief voor de SCL-9o. Maandblad Geestelijke volksgezondheid, 61, 120-141.

Elliott, R., Slatick, E. \& Urman, M. (2001). Qualitative Change Process Research on Psychotherapy: Alternative Strategies. Psychologische Beiträge, 43, 69-111. 
Franssen, A. \& Stinckens, N. (2005). Nederlandstalige vertaling van het Client Change Interview van Elliott. Intern document. Leuven: Centrum voor Cliëntgericht-experiëntiële Psychotherapie en Counseling, KU Leuven.

Hafkenscheid, A. (2004). De interpersoonlijke communicatietheorie van Donald J. Kiesler. Psychopraxis, 6, 15-19 en 59-64.

Horvarth, A.O. \& Greenberg, L.S (1989). Development and validation of the Working Alliance Inventory. Journal of Counseling Psychology, 36, 223-233.

Jacobson, N.S. \& Truax, P. (1991). Clinical significance: a statistical approach to defining meaningful change in psychotherapy research. Journal of consulting and clinical psychology 59: 12-19

Kessel, W. van \& Lietaer, G. (1998). Interpersonal processes. In L.S. Greenberg, J. C. Watson \& G. Lietaer (Eds.), Handbook of experiential psychotherapy (pp. 155-177). New York: Guilford.

Kiesler, D.J. (1996). Contemporary interpersonal theory and tesearch. Personality, psychopathology and psychotherapy. New York: Wiley.

Llewelyn, S. (1988). Psychological therapy as viewed by clients and therapists. British Journal of Clinical Psychology, 27, 223-238.

Sachse, R. (1997). Persönlichkeitsstörungen. Psychotherapie dysfunktionaler Interaktionsstile. Görringen: Hogrefe.

Safran, J.D. \& Muran, J.C. (2000). Negotiating the therapeutic alliance: A relational treatment guide. New York: Guilford Press.

Stinckens, N., Elliott, R. \& Leijssen, M. (2009). Bridging the gap between therapy research and practice in a person-centered/experiential therapy training program. The Leuven systematic case-study research protocol. Person-centered and Experiential Psychotherapies, 8 , 143-162.

Stinckens, N., Claes, L. \& Ulburghs, A. (2009). De werkalliantie als sleutelelement in het therapiegebeuren. Meting met behulp van de WAV-12, de Nederlandstalige verkorte versie van de Working Alliance Inventory. Tijdschrift voor klinische psychologie, 39, 44-60.

Swildens, H. (1997). Procesgerichte gesprekstherapie. Inleiding tot een gedifferentieerde toepassing van de cliëntgerichte beginselen bij de behandeling van psychische stoornissen (herziene druk). Utrecht: De Tijdstroom.

Vanaerschot, G. (1997). Plaats en betekenis van de empathische interactie in belevingsgerichte psychotherapie. Theoretische en empirische exploratie. Niet-uitgegeven doctoraatsproefschrift, KU Leuven.

Vanaerschot, G. (2008). Differentieel empathisch interactieaanbod. In G. Lietaer, G. Vanaerschot, J.A. Snijders \& R.J. Takens (red.), Handboek gesprekstherapie. De persoonsgerichte experiëntiële benadering (pp. 347-370). Utrecht: De Tijdstroom.

Verheul, R., Brink, W. van den \& Velden, K. van der (200o). Persoonlijkheidsstoornissen. In W. Vandereycken, C.A.L. Hoogduin \& P.M.G. Emmelkamp (red.), Handboek psychopathologie: deel 1 (pp. 407-432). Houten/Diegem: Bohn Stafleu Van Loghum.

Warner, M.S. (1992). Fragiele processen. Psychotherapeutisch Paspoort, 5, 105-118.

Wollants, G. \& Lietaer, G. (20oo). De existentiële dimensie. De betekenis van het existentieel-fenomenologisch gedachtegoed voor de psychotherapeutische praktijk. In W. Trijsburg, S. Colijn, E. Collumbien \& G. Lietaer (Eds.), Handboek Integratieve Psychotherapie (II.4, pp. 1-31). Utrecht: De Tijdstroom.

Wollants, G., Missiaen, C. \& Leys, C. (Eds.) (2004). Ervaringsgerichte begeleiding van A tot Z. Uitgegeven in eigen beheer (Faculteit Mens en Samenleving). 